\title{
No Looking Back: [Food]ways Forward for Healthy African Cities in Light of Climate Change
}

\author{
Jane Battersby (D) Jo Hunter-Adams
}

Published online: 9 March 2020

(C) The New York Academy of Medicine 2020

\section{Introduction}

The recent IPCC Climate Change and Land Report [1] lays out evidence of the need for urgent shifts in the global systems in light of climate change. This commentary reflects on Chapter 5, the Food Security chapter, from our perspective as researchers focused on urban food systems and non-communicable disease in Africa. Chapter 5 states that "transformational change will require integration of resilience and mitigation across all parts of the food system including production, supply chains, social aspects, and dietary choices" [1]. The report also argues that the current food system requires transformation to address the relatively high cost of nutritious foods, which is a contributing factor to obesity and non-communicable disease. Like the EAT-Lancet Commission report [2], the IPCC Climate Change and Land Report advocates for a diet that is both healthy for the individual and healthy for the planet.

While largely framed in the report and the literature more broadly as aspatial, with an implied rural focus, we argue that changing diets in a way that preserves health of people and plant must incorporate an explicitly urban lens. Not only is the global population now predominantly urban, but many key functions of the food system operate within the jurisdictional boundaries of city governments. An opportunity for national and local governments to engage food security and food systems governance as urban issues arose with the endorsement of the New Urban Agenda at the UN General Assembly in 2016 [3]. This document identified food security and nutrition as a key urban challenge (Para 2) and a public good to be provided by cities (Para 13). It further identifies food as a basic service in the same category of more conventionally accepted basic urban services, such as housing, water, and sanitation (Para 34). Paragraph 123 calls for food system governance and planning at the urban and territorial scales.

It is within this context that we argue for an explicitly urban lens to be brought to the IPCC's call for food system transformation. For the African context, in which we work, there must be a reimagining of the urban development trajectory. Given the reality of large urban populations, climate change, food security, and NCDs must all be central to the urban policy agenda. Cities should no longer look on economic growth as their measure of successful governance, nor on job creation: in retrospect, this approach has served neither planet nor people. Rather, the success of urban policy must be measured by its ability to support health. In the context of climate change and burgeoning NCDs

J. Battersby $(\bowtie) \cdot J$. Hunter-Adams

University of Cape Town African Centre for Cities, Cape Town, South Africa

e-mail: jane.battersby.lennard@gmail.com 
prevalence in urban Africa, it is essential for urban governments to proactively shape their food systems.

Urban policy must explicitly account for externalities including both health and environmental costs. In many ways, current trends in South Africa already echo with the implications of these externalities: the urban poor are often food insecure [4]. As a result of lack of dietary diversity and poor living conditions, the urban poor suffer from a complex set of diseases, including type II diabetes and hypertension and their corollary illnesses occurring in ever-younger urban populations [5]. As such, we propose an approach to urban development that integrates individual and planetary health [6]. Here, while job creation and economic growth are often considered top of pro-poor agenda, the long-term implication, and quality of employment (does it promote the long-term health of employees and of their environment?) must be prioritized. While the prioritization of any and all employment has previously seemed central to the well-being of the poor, cities must now prioritize health creation over wealth creation [7].

Further, it is within their powers to do so. City governments in Africa largely assume that they have no food mandate. However, all city governments are directly or indirectly involved in the governing of the urban food system, from public health permits, to issuing of trading permits, to zoning approvals for supermarkets, to the management of transport interchanges, to name but a few. Municipalities are involved in many facets of governing the food system and food security outcomes even if this is not explicitly recognized. This fundamentally shapes the experience of food security in urban areas [8]. For this reason, the City of Cape Town's new Resilience Strategy, which identifies the establishment of a food systems program as a flagship action to increase urban resilience is an important advance in policy thinking in African cities [9].

In the sections below, we suggest a selection of food specific and food sensitive interventions.

\section{Urban Food Production: Creation of Jobs in Food Production and Urban Waste Remediation}

The urban component of food system is explicitly engaged only in Section 5.6.5, which focuses primarily on urban agriculture. This section highlights that cities are drivers of food systems change, that urban food consumption is one of the largest sources of urban material flows, and that urban sprawl may be eroding food security through the loss of peri-urban agricultural land. It further identifies a number of ways in which urban and peri-urban agriculture contributes to climate change adaptation and mitigation, including reducing transport distance, recycling organic waste and wastewater, reducing urban heat island effects, increasing water infiltration, and strengthening biodiversityrelated ecosystem services.

We support Section 5.6.5, but would argue that the potential benefits of urban agriculture extend beyond these, including those that are synergetic with human health. Other sections of Chapter 5 call for food system actions that have the particular potential within the urban environment, given geographical proximity and population densities. Biodiversity and fruit and vegetable production are vulnerable to climate change, yet increasing dietary proportions of fruit and vegetables is vital for climate-mitigating changes in diet and for human health. The peri-urban environment is uniquely positioned to provide fruits and vegetables close to market, while promoting general biodiversity and agro-biodiversity, due to the availability of labor and organic waste. Urban production may realize the goals of shorter transportation times and shortened supply chains. To promote such agrobiodiverse production, cities must support indigenous knowledge, seed sovereignty, and soil preservation through no-till agriculture. No-till agriculture is facilitated in part by the cultivation of perennial foods, which requires secure land tenure and upfront capital investment. Protection of urban agricultural land and promotion of urban agricultural employment offer long-term gains to both people and planet. Cities are therefore sites of significant opportunity for food system transformation, a vital transformation given in the context of increasing dietrelated illness.

Consideration of urban food governance for climate change mitigation and adaptation, as well as for the prevention of diet-related illness must include, but also extend beyond support for urban agriculture, towards developing sustainable food systems in which urban agriculture is part of a wider, connected set of strategies. Cities must explicitly take on the role of creating closed loops between production, consumption, and waste. 


\section{Agro-processing}

While the vast majority of scholarly and policy work on food security and climate change has focused on production, an estimated $35 \%$ of the food systems contribution to greenhouse gas emissions globally is the result of processing and distribution (approx. 23\%) and retail, preparation and cooking (approx. 12\%) [10].

Agro-processing commonly occurs within city boundaries. This provides an opportunity for local government to determine the characteristics of these activities. Ultra-processed foods are increasingly produced and consumed in African cities. These processors are often energy intensive, have lower employment to contribution to GDP contribution than smaller processors [11], (p. 86) and are implicated in rising NCDs burdens [12-14]. The environmental and health consequences of these large-scale processors of ultra-processed foods are significant.

Urban government support of agro-processing should therefore consider the health of the consumer and the health of the planet. Smaller-scale agro-processing which draws on more local supply chains and has shorter distribution chains has the capacity to create and distribute healthy, minimally processed food (e.g., drying or fermenting vegetables to extend shelf life) with potentially fewer fossil fuel inputs. Moreover, urban governments can encourage the development of closed loop processing systems in which biowaste from production, processing, and retail can be used as energy sources in processing or production. The prioritization of such businesses would have environmental, health, and employment benefits for cities.

\section{Transportation}

The report cites the value of improved transportation networks for food and nutrition security. At the urban scale, this need should be detailed in terms of the impact on both the planet and on urban residents themselves. The transport of food to and within cities is a source of air pollution and greenhouse gas emissions from urban transport [15], and yet food is largely off the transport planning agenda. Bicycle deliveries of eggs in Dar es Salaam, for example, bring over one million eggs into the city each week with minimal emissions [16], but the city's transport plan is focused on the development of new roads and transport infrastructure that provide no space for non-motorized transport. Moreover, the long transportation times of the urban poor is contributing to increased dependency on fossil-fuel intensive ready-toeat foods [17]. Urban government attention to transport equity in terms of people and products can provide opportunities for shorter supply chains, and more local production for local consumption by addressing issues of both supply and demand. This is of value to both people and planet.

\section{Conclusion}

The IPCC Climate Change and Land Report makes a compelling argument for the transformation of global food systems in the interests of climate change and human health. Given urbanization trajectories, it is critical that policy and planning attention be given to food systems transformation at the urban scale. Not only is it demographically necessary, but we argue that urban areas provide unique opportunities for innovation and transformation towards food systems that are climate resilient and health promoting.

Acknowledgments This work was supported Urban Food Systems Governance for NCD Prevention in South Africa, Kenya and Namibia (Nourishing Spaces) International Development Research Centre, Grant number 108458.

\section{References}

1. IPCC. Climate change and land: an IPCC special report on climate change, desertification, land degradation, sustainable land management, food security, and greenhouse gas fluxes in terrestrial ecosystems. IPCC; 2019. https://www.ipcc. ch/site/assets/uploads/2019/11/SRCCL-Full-ReportCompiled-191128.pdf. Accessed 5 Feb 2020.

2. Willett W, Rockström J, Loken B, et al. Food in the Anthropocene: the EAT-Lancet Commission on healthy diets from sustainable food systems. Lancet. United Nations. 2019;393(10170):447-92.

3. UN Habitat. Habitat III: new urban agenda. Quito Online Httphabitat3 Orgwp-ContentuploadsNUA-Engl Pdf UN Habitat. 2016.

4. Battersby J. Urban food insecurity in Cape Town, South Africa: an alternative approach to food access. Dev South Afr. 2011;28(4):545-61. https://doi.org/10.1080/0376835 X.2011.605572.

5. Mayosi BM, Flisher AJ, Lalloo UG, Sitas F, Tollman SM, Bradshaw D. The burden of non-communicable diseases in South Africa. Lancet. 2009;374(9693):934-47. https://doi. org/10.1016/S0140-6736(09)61087-4. 
6. Lang T, Rayner G. Beyond the Golden Era of public health: charting a path from sanitarianism to ecological public health. Public Health. 2015;129(10):1369-82. https://doi. org/10.1016/j.puhe.2015.07.042.

7. Buse K, Tanaka S, Hawkes S. Healthy people and healthy profits? Elaborating a conceptual framework for governing the commercial determinants of non-communicable diseases and identifying options for reducing risk exposure. Glob Health. 2017;13(1):34.

8. Battersby J, Haysom G, Tawodzera G, McLachlan M, Crush J. Food system and food security study for the City of Cape Town. 2014. http://www.afsun.org/wpcontent/uploads/2016/08/Final-Food-System-StudyReport_Corrected-_WITH-COUNCIL-REPORT.pdf. Accessed 5 Feb 2020.

9. City of Cape Town. Cape Town Resilience Strategy. Cape Town: City of Cape Town. 2019. http://resource. capetown.gov.za/documentcentre/Documents/City $\% 20$ s trategies \% 2 C \% 20 p 1 a n s \% 20 and $\% 20$ frameworks/Resilience_Strategy.pdf. Accessed 5 Feb 2020.

10. FAO. "Energy-Smart" Food for People and Climate: Issue Paper. Rome: Food and Agriculture Organization of the United Nations; 2011.

11. DTI (South African Department of Trade and Industry). Industrial Policy Action Plan: Economic Sectors and Employment Cluster. IPAP 2013/2014Y2015/16. Pretoria: DTI; 2013.
12. Monteiro C, Nutrition and health. The issue is not food, nor nutrients, so much as processing. Public Health Nutr. 2009;12(05):729. https://doi.org/10.1017 /S1368980009005291.

13. Monteiro CA, Cannon G. The impact of transnational "big food" companies on the south: a view from Brazil. PLoS Med. 2012;9(7):e1001252.

14. Monteiro C, Moubarac J, Cannon G, Ng SW, Popkin B. Ultra-processed products are becoming dominant in the global food system. Obes Rev 2013;14(November):21-28. doi:https://doi.org/10.1111/obr.12107

15. Roberts W. The way to a city's heart is through its stomach. Toronto: Published by the Toronto Food Policy Council; 2001.

16. Wegerif MC. Exploring sustainable urban food provisioning: the case of eggs in Dar es Salaam. Sustainability. 2014;6(6):3747-79.

17. Hunter-Adams J, Battersby J, Oni T. Food insecurity in relation to obesity in peri-urban Cape Town, South Africa: implications for diet-related non-communicable disease. Appetite. 2019;137:244-9. https://doi.org/10.1016/j. appet.2019.03.012.

Publisher's Note Springer Nature remains neutral with regard to jurisdictional claims in published maps and institutional affiliations. 